\title{
FEATURES OF NETWORK INTERACTION IN THE AVIATION INDUSTRY OF RUSSIA IN THE CONTEXT OF DIGITIZATION
}

\author{
MINGALEVA Zhanna ${ }^{1}$, POSTNIKOV Vladimir ${ }^{2}$, KAMENSKIKH Mariia ${ }^{3}$ \\ 1 Perm National Research Polytechnic University (RUSSIA) \\ 2 Perm National Research Polytechnic University (RUSSIA) \\ 3 Perm National Research Polytechnic University (RUSSIA) \\ E-mails: mingal1@pstu.ru; postnikov-pstu@mail.ru;permmak13@gmail.com \\ This research was partially supported by the Ministry of Education and Science of the Russian Federation to Perm National \\ Research Polytechnic University (topic № FSNM-2020-0026).
}

\begin{abstract}
This article is devoted to issues of network interaction in the aviation industry in Russia, taking into account the trends and conditions of digitization. Networking is essentially the best way to integrate business, scientific and educational organizations and authorities. Digitization allows management decisions to be made faster and more efficiently, especially with the help of IT, to accelerate the creation and commercialization of innovations, and to engage new stakeholders in networking. Each interaction participant benefits from digital networking. In turn, the aviation industry is a priority for Russia and for other leading countries of the world. The article considers the possibility of developing network interaction in the aviation industry of Russia in the direction of creating an aerospace composite cluster in the context of digitalization. The experience of other Russian regions in which aviation clusters have already been formed has been analyzed. An analysis of the dynamics of industrial production capacities showed that the regions in which aviation clusters began to function show a significant positive dynamics in the volumes of shipped products. The development of network interaction in the aviation industry will increase the innovative component in the industry, strengthen the competitiveness and stability of the aviation industry in the context of digitization. One of the most significant processes in the framework of network interaction is the transfer of knowledge and technology especially with helping of IT.
\end{abstract}

Key words: network interaction; digitalization; innovation; business, science; authorities; regional development

$J E L: C 45$

DOI: 10.5937/intrev2103042M

UDC: 005.591.6:004.738]:629.7(470)

001.895

COBISS.SR-ID 55090953 


\section{INTRODUCTION}

In an unstable or crisis environment, economic actors seek cooperation and integration, which is reflected in the development of networking at various levels. Networking is perceived as a tool that contributes to the innovative development of both the participants in the interaction and individual regions, industries and countries in general. Networking is the basis for the creation of modern clusters.

At present, network interaction contributes to increasing the competitiveness and sustainable development of entities, taking into account digitalization trends [1]. The goal, prospects and problems of cluster development in the aviation industry are being actively discussed at the national level. The panel discussion on the topic "Aviation clusters of Russia and Europe", which was attended by the governors of all regions of Russia where there are aviation clusters, was held within the framework of the international air show MAKS-2019 [2]. The issues of creating a larger interregional aviation cluster, the possibility of developing second and third-tier suppliers in the aircraft industry, the introduction of relevant cooperation formats in the innovation sphere in Russia and others were among the key topics of discussion. And its accomplishment of these tasks is directly related to the possibilities and technologies of networkization and digitization.

The purpose of this article is to study the conditions of stable cluster development and effective network interaction of the aviation industry of Russia, taking into account the specifics of its structure, features of functioning and specifics of interaction of organizations, the prospects and the capabilities for the introduction of digital technologies.

The expansion of networking and the creation of competitive clusters in the aviation industry is made possible by the specifics of production processes, supply chains, industry structure and scale, and integrating institutions.

Signs of expanded network interaction in the aviation industry are manifested in the commonality of state standards and continuity of technological processes: from production and operational technologies to training technologies and the organization of experimental work. At the same time, for the practice of developing network interaction, the problem of combining strict administrative regulation of air transport and the need for market self-organization of its enterprises during the process of digitalization is significant.

\section{LITERATURE REVIEW}

The issues of cluster organization of the aviation sector in the scientific literature are still poorly disclosed.

Mathematical methods have already been developed and presented to analyze such issues of organizing a cluster of the aviation industry as: cluster scheme of the process of coordinating technological innovations in the aviation industry [3], assessing the competitiveness of the aviation industrial cluster [4], assessing the aviation industry cluster maturity [5]. These models have been tested with China's aviation clusters.

Research on networking in the establishment of an aviation industry cluster has received increasing attention in recent years. Most research works indicate that network interaction is developing more actively in those regions where the concentration of interconnected industries is high [6-7]. This factor can be considered as a historically formed prerequisite for networking in the aviation sector [8-9].

In Russia, networking in the aviation industry is developing around aircraft manufacturing enterprises, includes scientific and educational organizations (historically OKB and production were a single whole), and also involve infrastructure air enterprises serving air travel in interaction [10]. Such a combination of high-tech industries and scientific and educational organizations is usually formed in large administrative centers where airlines and/or regular air transportation are based.

We share the opinion of Danilochkina N. G. [11] and a number of other specialists that in industries whose products have a long life cycle, products should be understood not only as finished products, but as a set of services for the operation of these products. This range of services includes monitoring the technical condition of the fleet of products in operation, forecasting and diagnostics of malfunctions, maintenance and repair, logistic support (replenishment and supply of spare parts, replacement products, consumables, etc.), modernization aimed at improving the reliability, safety, environmental friendliness and economic efficiency of production. It is precisely such processes that occur in the field of aircraft engineering, while manufacturers and airline operators interact on an ongoing basis. 


\section{RESEARCH HYPOTHES}

Research hypotheses are proposed as follows:

$\mathrm{H}$ : The following research hypothesis is proposed: $\mathrm{H}$ : The Russian aviation industry has all the elements and institutional conditions for creating effective aviation clusters in key regions of Russia.

\section{MATERIALS AND METHODS}

\section{METHODS OF RESEARCH}

The study of the prospects for the development of regional aviation clusters in Russia was carried out on the basis of official statistics, as well as on the basis of a content analysis of the sectoral structure of the economy of a particular region, on the territory of which the aviation cluster operates - the Perm Krai.

Product life cycle and value chain approaches were used as a methodological basis for the selection of enterprises that may be part of an interregional aviation cluster.

In accordance with the approach of the life cycle of products (aviation technology), the aviation cluster should include all types of enterprises and organizations involved in the production and operation of aircraft. In a broad sense, these include:

- aircraft manufacturing enterprises (assembly, assembly and modular, modular and detailed);

- airlines;

- ground infrastructure enterprises (airports, airfields, enterprises for integrated ground maintenance of air transportation);

- scientific and educational organizations.

The interaction of all these enterprises within the framework of a single network interaction is due to the interconnectedness of the life cycle of aviation products.

In accordance with the "value chain" approach (in a narrower context), all participants in networking in the aviation industry can be conditionally divided into three groups:

1) assembly enterprise is a basic organization producing integrated final products or products of the first level of integration (aircraft, helicopters, convertiplanes, engines) and engaged in the disposal of aircraft are according to the All-Russian Classification of Economic Activities (OKVED), aircraft production is assigned to the subgroup 35.30.3;

2) enterprises and organizations providing basic organization with units, units and other components; raw materials and materials; services of public utilities, electric, thermal energy, etc. (resource level) are according to OKVED, this is 35.30.5 "Production of other parts and accessories of aircraft and spacecraft";

3) infrastructure organizations of the non-production sphere, commercial and non-commercial are codes according to OKVED 73.10 - "Scientific research and development in the field of natural and technical sciences," 80.30.1 - "Training in educational institutions of higher professional education," 65.22.2 - "Provision of industrial loans."

During the research, standard methods of statistical analysis were used based on Rosstat data for 20082019, regional statistics data, logical modeling methods, etc.

Also, to create a conceptual model for the functioning of aviation clusters in Russia and determine the directions of their development, the practical experience of organizing network interaction of aviation industry enterprises in the Perm Krai was used. 


\section{CASE STUDIES}

In the aviation industry of the Perm Krai, the most interesting and large-scale were the "Projects for the creation of aircraft engines PD-14 and PD-35", implemented by JSC UEC-Aviadvigatel and JSC UECPerm Motors [12]. The volume of investments in the project to create an aircraft engine PD-14 is 129.8 billion rubles, investments in the creation of an engine PD-35 - 180 billion rubles. Within the project on creation of the aviation PD-14 engine the JSC Perm Plant Mashinostroitel enterprise implements the investment project "Preparation of Mass Production of Knots of Motor-gondolas and Engines for the PD14 Propulsion System", the volume of investment is 1.9 billion rubles.

The creation of the PD-14 engine was the main achievement of recent years in the domestic civil aircraft engine industry. The development of the PD-35 engine for promising wide-body long-haul aircraft is based on the experience of creating the PD-14 engine for the MC-21-300 airliner. It is on the basis of JSC UEC-Perm Motors that the first complex in Russia will appear for testing new high-thrust aircraft engines, such as PD-35.

Also in this industry, the project "Reconstruction and technical re-equipment of the bench base for testing the transmission units of the helicopters of PJSC" Aviation reduction gears and transmissions are Perm motors, "implemented by JSC" Reductor-PM", investment volume is 2.6 billion rubles.

The key organizations that implement network cooperation in the aviation industry of the Perm Krai are PJSC Proton PM and FSBOU VPO Perm National Research Polytechnic University (PRNPU). PJSC ProtonPM specializes in the manufacture of RD-276 liquid-propellant rocket engines used as an energy plant of the first stage of Proton-M heavy-class launch vehicles. Today, the company is developing the production of new generation engine units and assemblies RD-191 for the promising Angara launch vehicle family.

The goal of networking the aviation industry of the Perm Krai is to concentrate the intellectual, personnel, technological and production potentials of enterprises, research and educational organizations of the Perm Krai on the basis of a single geographical space and a single scientific, technical and socioeconomic infrastructure. At the same time, it is planned to develop network interaction with organizations from other countries and regions. Enterprises and territories of the Perm Territory are highly susceptible to innovation [13].

The development of network interaction in the aviation industry of the Perm Krai is associated with the strategic interests of the Russian Federation in the field of missile engineering.

The advantage of interaction is the close cooperative ties of many enterprises and organizations. In particular, there are 8 enterprises in cooperation (with an annual revenue from the sale of products of more than 1 billion rubles) are manufacturers and developers of products of space and aircraft propulsion, other sectors of mechanical engineering, energy and metallurgy.

Also, the advantage of interaction is the presence in the region of leading scientific centers: the Institute of Continuous Media Mechanics of the Ural Branch of the Russian Academy of Sciences, the Institute of Technical Chemistry of the Ural Branch of the Russian Academy of Sciences, the Center for Powder Materials Science, the Center for Prototyping and Progressive Technologies of Mechanical Materials Processing, the Center for Parallel and Distributed Computing Technologies in Engine Engineering, Engineering Services, Engineering and others.

As part of the implementation of this direction, production and scientific cooperation is successfully developing in the Perm Krai: PJSC Aviadvigatel and PJSC NPO Iskra are developers of energy equipment; PJSC Perm Motor Plant, PJSC Proton-PM, Iskra-Turbogaz LLC are serial manufacturers of products; Iskra-Avigaz JSC and Iskra-Energy PJSC are engineering and service companies.

Organizations involved in network interaction in the aviation industry of the Perm Krai are presented in Fig. 1. 


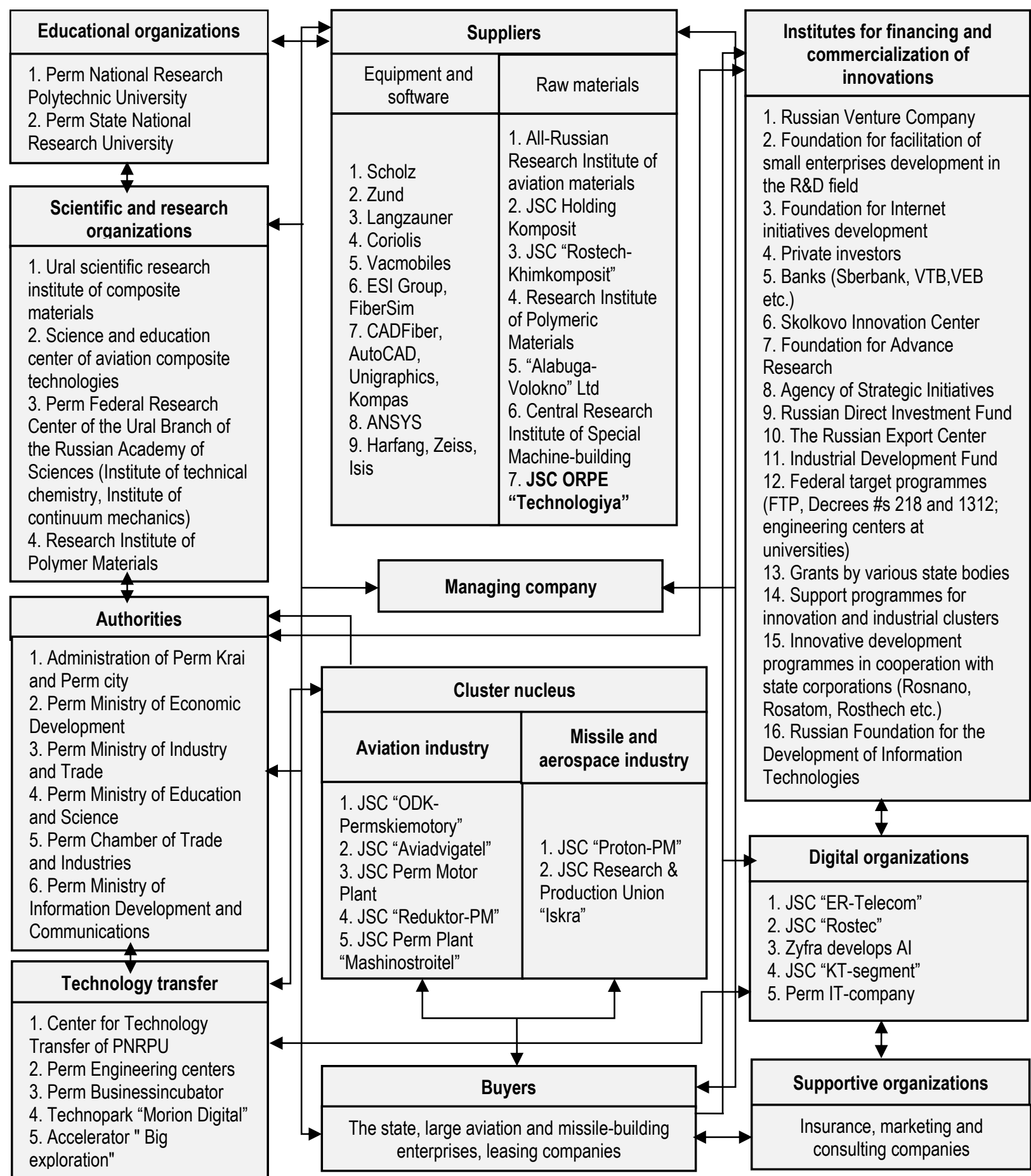

Source: adapted by the authors [14]

\section{Figure 1: Organizations involved in network interaction in the aviation industry of the Perm Krai}

In addition to the work of the main topic, that is rocket engine building, the enterprises of the aviation industry carry out joint work on the development of aviation engine building and energy engineering. Key projects were implemented with the involvement of scientific centers, leading national research universities of the Perm Krai and the Ural Branch of the Russian Academy of Sciences.

The presented here list of cluster participants demonstrates that many organizations are already in cooperation on very similar issues, and this would ease communication in the process of cluster establishment and during the formation of environment for data exchange based on the principles of open innovations. 


\section{RESEARCH RESULTS}

Stable development of network interaction in the aviation industry is possible under the following conditions:

- administrative support for the activities of air enterprises and the harmonization of regional development goals with the goals of the participants in the interaction;

- the creation of a favourable investment climate in the region;

- a system for monitoring the efficiency of the use of budgetary and extrabudgetary funds aimed at projects implemented by the aviation industry;

- building a regulatory framework that supports the development of small and medium-sized businesses, both in the field of production and service, and in the field of scientific development;

- activity of scientific and educational organizations of the region and their integration into the network interaction system.

The networking structure shall consist of several loops (Figure 2).

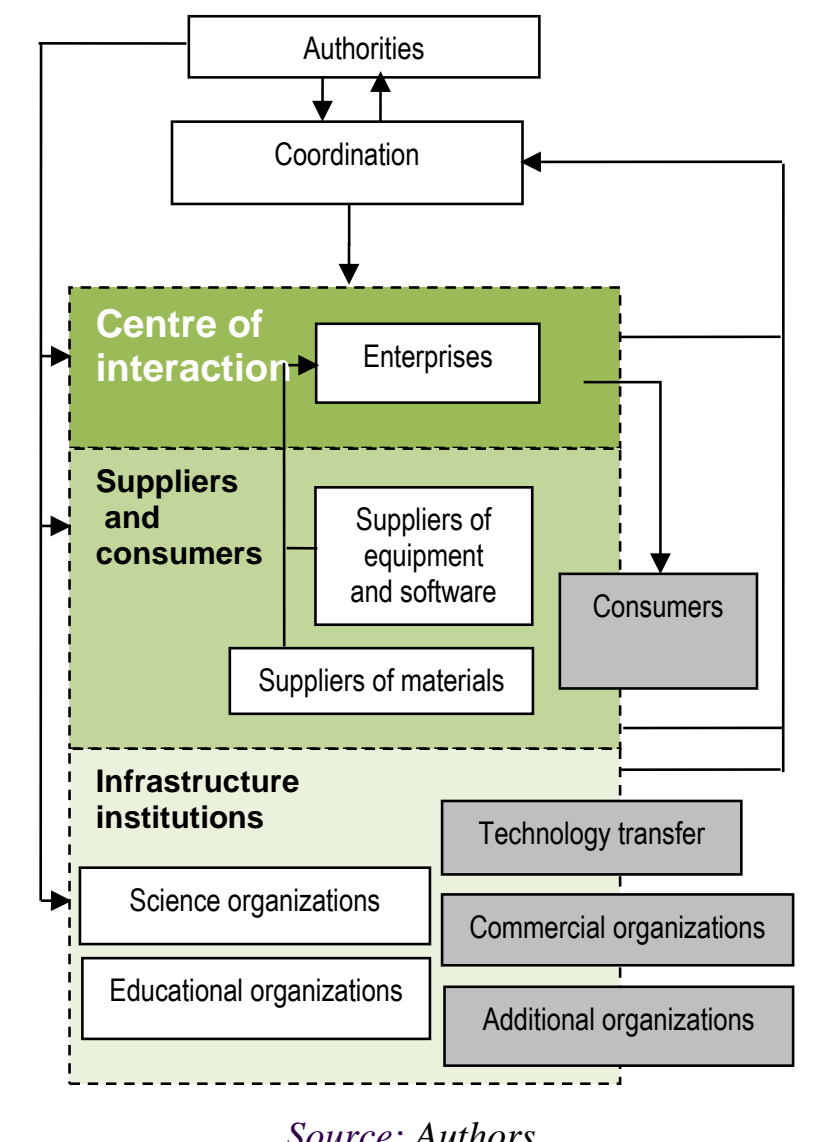

Figure 2: Aviation cluster network structure model

The first circuit consists of the core of network interaction, which includes the main production enterprises.

The second contour includes the enterprises and the organizers providing an interaction kernel with raw materials, materials, the equipment and the software and also buyers of products.

The third circuit includes infrastructure organizations: educational and research organizations, institutes of commercialization, financing and technology transfer.

The interaction development strategy and coordination between its participants is managed by the interaction management company, which is an independent business unit.

The management board (coordinating board - of the interaction management company should include a representative of all enterprises of the interaction core, but the management should be carried out by an 
independent director who takes into account the interests of all participants in the interaction, and acts to develop interaction and industry in the region.

The main function of the management company is to coordinate the interests of participants in interaction with each other, with public authorities and business entities located in the environment external to the cluster under consideration. This approach to the construction of interaction includes all the main stages of the life cycle of innovative products: scientific research $\rightarrow$ applied research $\rightarrow$ development developments $\rightarrow$ technology transfer $\rightarrow$ technology commercialization $\rightarrow$ finished products production $\rightarrow$ after-sales service $\rightarrow$ recycling. This approach is based on using digitalization trends.

\section{BENEFITS OF NETWORKING FOR MEMBERS}

- compensation of costs for acquisition or creation of resources (high-tech jobs, advanced technologies, high-tech production) [15];

- increasing the availability of financial resources through credit cooperation, that is mutual lending, guarantees and guarantees [16];

- reduction of production costs, reduction of equipment acquisition costs;

- open access to infrastructure, no administrative barriers [17];

- utilization of the production potential of each interaction participant through the production cooperation;

- joint R \& D and technology transfer through research and technology cooperation [18];

- improving the quality of education, developing and implementing advanced scientific developments and technologies through the collaboration of universities and enterprises [19-20];

- development of a single brand used by all members of the interaction, conducting joint marketing research through marketing cooperation;

- formation of a common information and communication space through information cooperation;

- creation of new highly skilled jobs [21].

- In general, network interaction allows the formation of a self-organizing structure in the aviation industry, which will ultimately lead to the reform of the aviation industry due to the self-organization of economic entities into horizontally integrated business groups through structural, technological and organizational transformation of enterprises and diversification of their activities.

- Self-organization based on networkization and digitization creates certain space for intercluster cooperation, and as European cluster experience [22] shows, this enhances cluster performance.

- We analyzed the dynamics about industrial production in 2008, 2012, 20162019 in the regions where aviation clusters were formed: Ulyanovsk, Samara, Nizhny Novgorod, Voronezh regions, Republic of Tatarstan, Khabarovsk Krai and Perm Krai (Figure 3).

- Periodization was chosen as follows:

- 2008 was the last pre-crisis year of sustained growth.

- 2012 was the year of creation of all analyzed clusters.

- 2016 was the year of ratification of the Paris Convention on Combating Climate Change (a significant increase in environmental requirements for aviation equipment and its operation and, accordingly, the introduction of changes in the technology for the production of aviation equipment) by Russia.

- 2019 was the year with last officially approved statistics.

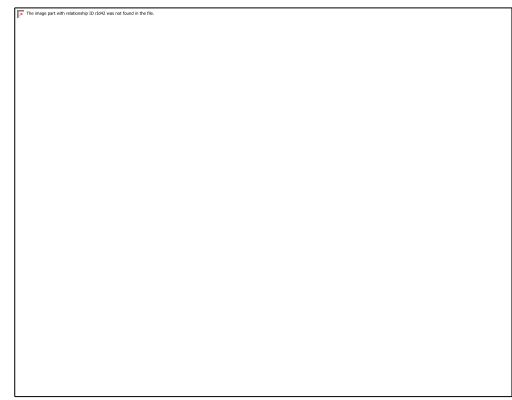

Source: Authors.

Figure 3: the dynamics of dynamics of industrial production in 7 regions - locations of aviation clusters in 2008-2019 
Figure 3 shows that in Russia there are two groups of aviation clusters characterized by different development indicators.

The first group includes 4 clusters, in which the initial data for development roughly coincided (regional production volumes were in the range of \$8-10 million). There are Nizhny Novgorod region, Republic of Tatarstan, Perm Krai, Samara region.

The second group includes 3 clusters located in the Voronezh region, Ulyanovsk region and Khabarovsk Krai.

These clusters of aviation specialization differ from other types of clusters, the main features of which are considered to be the geographical proximity of enterprises, their interaction in one or more close areas of the economy, the unity of their technological chains.

The important result of the analysis is that the growth rate of regional production in two groups was different. So in the first group the average growth over the period 2008-2019 years amounted to about 2.4 times. In the second group is about 3.4 times (See Table 1).

Table 1: Increase in industrial products production volumes of regions by periods (times
\begin{tabular}{|l|l|l|l|l|}
\hline Cluster's groups & Tame periods \\
\hline & $2012 / 2008$ & $2016 / 2012$ & $2019 / 2016$ & $2019 / 2008$ \\
\hline 1-st group & & & & \\
\hline Nizhny Novgorod region & 1,41 & 1,39 & 1,20 & 2,35 \\
\hline Republic of Tatarstan & 1,66 & 1,44 & 1,35 & 3,23 \\
\hline Perm Krai & 1,34 & 1,14 & 1,33 & 2,04 \\
\hline Samara region & 1,35 & 1,37 & 1,11 & 2,06 \\
\hline 2-nd group & & & & \\
\hline Voronezh region & 1,79 & 1,66 & 1,22 & 3,62 \\
\hline Ulyanovsk region & 1,51 & 1,49 & 1,34 & 3,04 \\
\hline Khabarovsk Krai & 1,15 & 1,71 & 1,73 & 3,38 \\
\hline
\end{tabular}

The study revealed the presence of a significant economic effect that positively affects the economic development of regions with aviation clusters.

During this period, they experienced a multiple increase in industrial production. This trend is not accidental, but is due to the development of cluster structures of the aviation profile: they generate associated production, contribute to the increase of human resources and personnel capacity of the region, and attract investment in the regional economy.

\section{DISCUSSIONS}

Based on the analysis carried out, we believe that when deciding on the development of territorial aviation clusters and when creating an interregional aviation cluster, it is necessary to take into account the main effects that can be obtained by various entities from the activities of the cluster (see Table 2).

Table 2: Economic effects network cooperation aviation industry with helping IT

\begin{tabular}{|l|l|l|}
\hline $\begin{array}{l}\text { Effects for } \\
\text { enterprises }\end{array}$ & Effects for regional industry & Effects for regional economy \\
\hline low transport costs & increasing production & increasing GRP \\
\hline $\begin{array}{l}\text { decreasing } \\
\text { transactional costs }\end{array}$ & $\begin{array}{l}\text { increasing effect-iveness on the basis } \\
\text { increasing competitiveness }\end{array}$ & $\begin{array}{l}\text { development small and } \\
\text { medium enterprises }\end{array}$ \\
\hline $\begin{array}{l}\text { common using of } \\
\text { infrastructure }\end{array}$ & $\begin{array}{l}\text { strengthening ties between enter-prises, } \\
\text { science and educational institutions }\end{array}$ & $\begin{array}{l}\text { increasing regional investment } \\
\text { attractiveness }\end{array}$ \\
\hline knowledge transfer & development innovations in industry & $\begin{array}{l}\text { improving the sustainability of } \\
\text { the regional economy }\end{array}$ \\
\hline additional revenue & new forms of business & rising tax revenues \\
\hline
\end{tabular}

Source: Authors 
Three groups of effects can be distinguished from network interaction in the aviation industry during the process of digitalization. Integration leads to positive changes in the structure of capital, in which its form appears as cluster capital - the combined economic relations of economic entities regarding the receipt of value added, the interaction of which is due to a long-term connection industrial, financial and credit, human, communicative capital. Cluster capital is a complex entity in which the following main forms can be distinguished [23]:

- structural capital are non-financial assets of participants, networks;

- cognitive capital are common values, codes, language, interaction;

- interrelating capital are financial assets, trust, norms, liabilities, identification and control;

- innovative capital are generation of results of innovative interaction and development of the gross regional product of the Krai where it was created.

The development of network interaction gives rise to related industries, contributes to the increase of human resources and personnel potential of the region, and attracts investments in the regional economy. One more the same Russian case can be found in Sverdlovsk region, when cluster and agglomeration approaches integrated in the project of Big Yekaterinburg in industrial, financial and ITC clusters [24].

Technological reasons for network interaction are related to the need for basic and applied research in the design of new aircraft. In addition, it is more rational to manufacture many components in the cooperation of specialized enterprises, and not at a universal giant enterprise. The development of network interaction intensified with the rise of industrial innovative production in the 2000s [25][26]. After 2012 negative trends in the economy of the Russian Federation increased, which pushed enterprises to consolidate, and integration processes intensified.

The development of network interaction ensures not only increasing the competitiveness of its cooperative enterprises, but also stimulates research and development, contributes to the formation of small and medium-sized businesses around key enterprises of the aviation industry, which, in the end, brings significant effects for the regional and national economy [27][28].

\section{CONCLUSIONS}

So, network interaction brings a number of benefits to both participants in interaction are enterprises, scientific and educational organizations, authorities, and regional industry and the regional economy as a whole. The aviation industry is significant both for Russia as a whole and for specific regions.

The development of network interaction in the aviation industry will lead to an increase in the innovative component, an increase in tax revenues to the regional budget and an increase in the competitiveness of participants in the interaction

Further direction of research may be aimed at determining indicators reflecting the level of network interaction in the aviation industry of the region during process of digitalization, and developing a methodology for assessing the level of network interaction in the aviation industry with the aim of further development of a control system based on networking and digitalization.

\section{ACKNOWLEDGMENT}

This research was partially supported by the Ministry of Education and Science of the Russian Federation to Perm National Research Polytechnic University (topic № FSNM-2020-0026).

\section{REFERENCES}

[1] Mingaleva Z., Deputatova L., Starkov Y.(2020) "Management of Organizational Knowledge as a Basis for the Competitiveness of Enterprises in the Digital Economy", Lecture Notes in Networks and Systems, vol.78, 203-212, doi.org/10.1007/978-3-030-22493-6_18

[2] Aviation clusters of Russia and Europe with the participation of governors (Republic of Tatarstan, Perm Territory, Samara Region, Ulyanovsk Region), www.https://aviasalon.com/ru/programs/aviation-clusters-of-russia-and-europe 
[3] Li, H. Ma, X.-B. Li, X.-G.(2010) "A research on process pattern of technology innovation coordination within the aviation industry cluster", Proceedings - 3rd International Conference on Information Management, Innovation Management and Industrial Engineering, ICIII 2010, Vol. 3 , 337-340. DOI: 10.1109/ICIII.2010.401

[4] Zhu, Y., Han, Q. (2013) "Research on grey relational evaluation of the competitiveness of aviation industrial cluster: By taking Xi'an Yanliang aviation park as an example", Journal of Grey System, Vol.25, No. 4, 62-70.

[5] Zhai, T., Zhu, Y., Han, Q.(2014) "Research on grey-fuzzy comprehensive evaluation of aviation industry cluster maturity by taking Xi'an Yanliang aviation park as an example", Conference Proceedings - IEEE International Conference on Systems, Man and Cybernetics; Vol. January, 20552059. DOI: $10.1109 / \mathrm{smc} .2014 .6974224$

[6] Confraria, H., Vargas, F.(2019) "Scientific systems in Latin America: performance, networks, and collaborations with industry". J Technol Transf, Vol.44, 874-915, doi.org/10.1007/s10961-0179631-7.

[7] Khroni, K.O.(2013) "Features of modernization of the aviation industry", Problems of economics and management, Vol. 11, No. 27, 81-84.

[8] Ozkok, O., Bell, S.J., Singh, J. et al. (2019)"Frontline knowledge networks in open collaboration models for service innovations", AMS Rev, Vol. 9, 268-288, doi.org/10.1007/s13162-018-00133-5

[9] Lublinski, A.E. (2003)"Does geographic proximity matter? Evidence from clustered and nonclustered aeronautic firms in Germany", Regional Studies, Vol. 37, No. 5, 453-467, doi: 10.1080/0034340032000089031

[10] Troshin, A.N., Fedorova, L.A. (2015)"Prediction of the stable development of knowledge-intensive industries in Russia's aviation cluster", Studies on Russian Economic Development, Vol. 26, No. 3, 233-240.

[11] Danilochkina, N.G., Zinchenko, A.S., Bobrova, M.B.(2018) "Analysis of the state and prospects for the development of the Russian aviation industry when adapting to environmental conditions", Bulletin of Moscow State Regional University. Series: Economics, Vol.3, 69-75.

[12] Tashkinov, A.G. (2018)"Development of a method for assessing the competitiveness of the production and economic system of a machine-building enterprise", PNRPU Bulletin. Socioeconomic sciences, Vol.4, 260-274.

[13] Mingaleva Zh., Mingaleva A. (2013)“Assessing Innovation Susceptibility of Regions And Municipal Districts”, Procedia-Social and Behavioral Sciences, Vol.81, 595599. doi:10.1016/j.sbspro.2013.06.482

[14] Andreeva, O. Yu., Postnikov, V.P.(2017) "Composite Cluster as a Factor of Aerospace Brach Development in Perm Krai", Journal of Advanced Research in Law and Economics, Vol. 8, No. 30, 2324 - 2333. DOI: 10.14505/jarle.v8.8(30).02.

[15] De Prato, G., Nepelski, D. (2014)“'Global technological collaboration network: network analysis of international co-inventions", J Technol Transf, Vol. 39,358-375, https://doi.org/10.1007/s10961012-9285-4

[16] Gao, S., Guo, Y., Chen, J. et al. (2016)“Factors affecting the performance of knowledge collaboration in virtual team based on capital appreciation”, Inf Technol Manag, Vol. 17,119-131, https://doi.org/10.1007/s10799-015-0248-y

[17] Mingaleva, Zh., Bykova, E., Plotnikova, E.(2013)"Potential of the Network Concept for an Assessment of Organizational Structure", Procedia-Social and Behavioral Sciences, Vol.81, 126130, doi:10.1016/j.sbspro.2013.06.400

[18] Hui, Z., Cai, X., Greneche, J. et al.(2011) "Structure and collaboration relationship analysis in a scientific collaboration network", Chin. Sci. Bull., Vol. 56,3702-3706. https://doi.org/10.1007/s11434-011-4756-9

[19] Lyu, L., Wu, W., Hu, H. et al.(2019) "An evolving regional innovation network: collaboration among industry, university, and research institution in China's first technology hub", J Technol Transf, Vol. 44,659-680, doi.org/10.1007/s10961-017-9620-x

[20] Mingaleva, Zh., Bykova, E., Lobova, G. (2013)"Motivation Processes of Educational Activities in Russia", Procedia-Social and Behavioral Sciences, Vol. 83,985-989,

doi:10.1016/j.sbspro.2013.06.183 
[21] Ceballos, H.G., Fangmeyer, J., Galeano, N. et al.(2017) "Impelling research productivity and impact through collaboration: a scientometric case study of knowledge management", Knowl Manage Res Pract, Vol. 15, 346-355, https://doi.org/10.1057/s41275-017-0064-8

[22] Aulkemeier, F., Iacob, M. \& van Hillegersberg, J. (2019)“Platform-based collaboration in digital ecosystems". Electron Markets, Vol. 29,597-608. https://doi.org/10.1007/s12525-019-00341-2

[23] Gorbachev, M.V., \& Gorbachev, V.I.(2013) "Innovations in the aviation industry and transport", Scientific bulletin of the Moscow State Technical University of Civil Aviation, Vol. 12, No. 198, 125-129.

[24] Vukovic, N., Larionova, V., Biryulina, V. (2018). The principles of the green economy in the context of agglomeration: evidence from Big Ekaterinburg.International Conference on Sustainable Cities.IOP Conf. Series: Earth and Environmental Science. 177. 012006

[25] Koren, A.V. (2017)"Strategic aspects of aviation industry development. Transport of the Russian Federation", Journal of Science, Practice, Economics, Vol. 3, No. 70, 3-6.

[26] Topoleva, T.N.(2018) "Formation of an innovative model for the development of industrial enterprises", PNRPU Bulletin. Socio-economic sciences, Vol. 4,220-231.

[27] Matsui, M.(2015) Economics of collaboration: Another medium flow/value approach to the invisible body-balancing economics for SCM/GDP. In Proceedings of 23rd International Conference on Production Research, Manila, Philippines.

[28] Chang H., Su. B., Zhou Y., He D.(2007) "Assortativity and act degree distribution of some collaboration networks", Phys A, Vol. 383, No. 2, 687-702.

\section{Article history:}

Received 21 January 2021

Accepted 7 September 